Psychological Medicine

http://journals.cambridge.org/PSM

Additional services for Psychological Medicine:

PSYCHOLOGICAL

MEDICINE

Email alerts: $\underline{\text { Click here }}$

Subscriptions: $\underline{\text { Click here }}$

Commercial reprints: $\underline{\text { Click here }}$

Terms of use : $\underline{\text { Click here }}$

\title{
Neurology out-patients with symptoms unexplained by disease: illness beliefs and financial benefits predict 1-year outcome
}

M. Sharpe, J. Stone, C. Hibberd, C. Warlow, R. Duncan, R. Coleman, R. Roberts, R. Cull, A. Pelosi, J. Cavanagh, K. Matthews, R. Goldbeck, R. Smyth, A. Walker, J. Walker, A. MacMahon, G. Murray and A. Carson

Psychological Medicine / Volume 40 / Issue 04 / April 2010, pp 689 - 698

DOI: 10.1017/S0033291709990717, Published online: 23 July 2009

Link to this article: http://journals.cambridge.org/abstract_S0033291709990717

How to cite this article:

M. Sharpe, J. Stone, C. Hibberd, C. Warlow, R. Duncan, R. Coleman, R. Roberts, R. Cull, A. Pelosi, J. Cavanagh, K. Matthews, R. Goldbeck, R. Smyth, A. Walker, J. Walker, A. MacMahon, G. Murray and A. Carson (2010). Neurology outpatients with symptoms unexplained by disease: illness beliefs and financial benefits predict 1-year outcome. Psychological Medicine, 40, pp 689-698 doi:10.1017/S0033291709990717

Request Permissions : $\underline{\text { Click here }}$ 


\title{
Neurology out-patients with symptoms unexplained by disease: illness beliefs and financial benefits predict 1-year outcome
}

\author{
M. Sharpe ${ }^{*}$, J. Stone ${ }^{2}$, C. Hibberd ${ }^{1}$, C. Warlow ${ }^{2}$, R. Duncan ${ }^{3}$, R. Coleman ${ }^{4}$, R. Roberts ${ }^{5}$, R. Cull ${ }^{2}$, \\ A. Pelosi ${ }^{6}$, J. Cavanagh ${ }^{7}$, K. Matthews ${ }^{5}$, R. Goldbeck ${ }^{4}$, R. Smyth ${ }^{8}$, A. Walker ${ }^{9}$, J. Walker ${ }^{1}$, \\ A. MacMahon ${ }^{9}$, G. Murray ${ }^{10}$ and A. Carson ${ }^{1}$ \\ ${ }^{1}$ Psychological Medicine Research, School of Molecular and Clinical Medicine, University of Edinburgh, UK \\ ${ }^{2}$ Department of Clinical Neurosciences, School of Molecular and Clinical Medicine, University of Edinburgh, UK \\ ${ }^{3}$ Institute of Neurological Sciences, Southern General Hospital, Glasgow, UK \\ ${ }^{4}$ Aberdeen Royal Infirmary, Aberdeen, UK \\ ${ }^{5}$ Ninewells Hospital, University of Dundee, Dundee, UK \\ ${ }^{6}$ Hairmyres Hospital, East Kilbride, UK \\ ${ }^{7}$ Sackler Institute of Psychobiological Research, Faculty of Medicine, University of Glasgow, UK \\ ${ }^{8}$ Royal Infirmary of Edinburgh, Edinburgh, UK \\ ${ }^{9}$ Robertson Centre for Biostatistics, University of Glasgow, Glasgow, UK \\ ${ }^{10}$ School of Clinical Sciences and Community Health, University of Edinburgh, UK
}

Background. Patients whose symptoms are 'unexplained by disease' often have a poor symptomatic outcome after specialist consultation, but we know little about which patient factors predict this. We therefore aimed to determine predictors of poor subjective outcome for new neurology out-patients with symptoms unexplained by disease 1 year after the initial consultation.

Method. The Scottish Neurological Symptom Study was a 1-year prospective cohort study of patients referred to secondary care National Health Service neurology clinics in Scotland (UK). Patients were included if the neurologist rated their symptoms as 'not at all' or only 'somewhat explained' by organic disease. Patient-rated change in health was rated on a five-point Clinical Global Improvement (CGI) scale ('much better' to 'much worse') 1 year later.

Results. The 12-month outcome data were available on 716 of 1144 patients (63\%). Poor outcome on the CGI ('unchanged', 'worse' or 'much worse') was reported by 482 (67\%) out of 716 patients. The only strong independent baseline predictors were patients' beliefs [expectation of non-recovery (odds ratio [OR] 2.04, 95\% confidence interval [CI] 1.40-2.96), non-attribution of symptoms to psychological factors (OR 2.22, 95\% CI 1.51-3.26)] and the receipt of illness-related financial benefits (OR 2.30, 95\% CI 1.37-3.86). Together, these factors predicted $13 \%$ of the variance in outcome.

Conclusions. Of the patients, two-thirds had a poor outcome at 1 year. Illness beliefs and financial benefits are more useful in predicting poor outcome than the number of symptoms, disability and distress.

Received 23 April 2009; Revised 8 June 2009; Accepted 16 June 2009; First published online 23 July 2009

Key words: Cohort study, medically unexplained symptoms, neurology, outcome.

\section{Introduction}

Patients whose symptoms are regarded as 'unexplained by disease' are frequently encountered in all medical settings (Gureje et al. 1997). Synonyms for such symptoms include 'medically unexplained', 'somatoform' and 'functional' (Sharpe, 2002). Symptoms

* Address for correspondence: M. Sharpe, M.A., M.D., FRCP, FRCPsych, Psychological Medicine Research, Kennedy Tower, Royal Edinburgh Hospital, Edinburgh EH10 5HF, UK.

(Email: Michael.Sharpe@ed.ac.uk) that are considered by the assessing doctors to be 'not at all' or only 'somewhat' explained by disease account for about a third of new out-patient visits to secondary medical care services, such as neurology out-patient clinics. They often do not improve after the specialist consultation (Carson et al. 2003) and may become associated with chronic disability (Carson et al. 2000; Kroenke, 2003). However, we know relatively little about which patient characteristics predict a poor post-consultation outcome for these patients.

Our aim was therefore to determine the patient characteristics that predicted a poor patient-reported 
1-year outcome for patients newly referred to neurology out-patient clinics with symptoms that were rated by the assessing neurologist as 'not at all' or only 'somewhat' explained by disease. Based on previous reports of predictors of subjective outcome in other similar symptomatic conditions, we hypothesized that the following variables would predict poor outcome: greater number of physical symptoms (Speckens et al. 1996b); poorer physical functioning (Carson et al. 2003); greater emotional distress (Bombardier \& Buchwald, 1995); general worry about health (Kroenke \& Jackson, 1998); the belief that they would not recover (Mondloch et al. 2001); the belief that the symptoms were not affected by psychological factors (Vercoulen et al. 1996) ; and being in receipt of illnessrelated financial benefits (Atlas et al. 2006).

\section{Method}

The study was part of the Scottish Neurological Symptom Survey, a prospective, multi-centre, Scottish national study of a representative cohort of newly referred neurology out-patients.

\section{Participating clinics}

Of the 38 consultant neurologists working in the four Scottish National Health Service (NHS) neurology centres, 36 participated. Patients were recruited from their general neurology clinics (including their supervised trainee clinics) in the main Scottish neurological centres (at Aberdeen, Dundee, Edinburgh and Glasgow, all in the UK) and some of their associated peripheral clinics (at Airdrie, East Kilbride, Falkirk, Inverness, Perth, Stirling, Vale of Leven and Wishaw, all in the UK) between December 2002 and February 2004. All the clinics sampled took mainly general practice referrals, with patients allocated by medical records staff according to availability of appointment. Specialist clinics, where patients required a suspected specific diagnosis to attend (such as acute neurovascular and multiple sclerosis clinics), were excluded as were 'urgent case' emergency clinics.

\section{Patients}

All patients newly referred to the participating neurology out-patient clinics were potentially eligible for inclusion. The exclusion criteria were: age $<16$ years, cognitive impairment of a degree that precluded informed consent, inability to read English, or if the neurologist identified the patient as unsuitable for the study (for example, too distressed or terminally ill). New patients included patients with existing neurological diagnoses who had been re-referred from primary care. Patients gave informed consent to be included in the study. We studied patients whom the neurologist had rated as having symptoms 'not at all' or only 'somewhat' explained by disease (see below)

\section{Procedure}

Patients were sent information about the study prior to their appointment with the neurologist. After the consultation the patients were invited by their neurologist to speak to a research assistant. Written consent was obtained from those patients willing to participate. A rating of how explained the symptoms were by disease was obtained from the assessing neurologist (see below). Baseline data were collected from the patients immediately after the initial consultation using a questionnaire. At 1 year after the initial consultation, outcome data were sought from the patients by questionnaires posted to their homes. Patients who failed to respond were sent another copy of the questionnaire and those who still failed to respond were contacted by telephone and reminded. Questionnaires were completed by telephone interview if necessary.

\section{Measures}

\section{Completed by neurologists}

The neurologists completed a questionnaire for each patient which asked, 'To what extent do you think this patient's clinical symptoms are explained by organic disease?' Responses were made on a four-point Likert-type scale: 'not at all', 'somewhat', 'largely' or 'completely' (Carson et al. 2000). Operational criteria were provided to guide these ratings (see Appendix). Patients whose symptoms were rated as 'not at all' or only 'somewhat' explained were combined to make a category of 'symptoms unexplained by disease'.

\section{Completed by patients}

The measures listed below were collected from the patient by questionnaire immediately after the initial consultation:

(1) Demographics: age, sex and marital status.

(2) Number of physical symptoms. This was measured using the Patient Health Questionnaire checklist of the 15 commonest physical symptoms presenting to primary care (excluding upper respiratory tract infections) and with the sexual and menstrual items removed to leave 13 items (Kroenke et al. 2002). In order to see if the inclusion of neurological symptoms made a difference we created a longer symptom score by supplementing 
these items with nine symptoms common in neurology patients judged to have symptoms unexplained by disease (Lempert et al. 1990) to make a 22-item scale. The total number of symptoms endorsed on each scale was calculated for each patient.

(3) Physical function. This was measured using the physical function subscale of the Medical Outcomes Study Short-Form 12-item Scale (SF12) (Ware et al. 1996).

(4) Emotional distress. This was measured by the total score on the Hospital Anxiety and Depression Scale (HADS) (Zigmond \& Snaith, 1983).

(5) Illness beliefs. Two categories of belief were assessed:

(a) patients' beliefs about outcome were measured using an item from the Illness Perceptions Questionnaire (IPQ; Weinman et al. 1996): 'My symptoms are likely to be permanent rather than temporary'. Responses were made on a five-point Likert scale ('strongly agree', 'agree', 'neither agree nor disagree', 'disagree', 'strongly disagree'). The responses 'agree' and 'strongly agree' were combined to indicate an expectation of poor outcome.

(b) patients' attribution of symptoms to psychological factors was measured using two other items from the IPQ. These were: 'Possible causes of my symptoms are stress or worry' and possible causes of my symptoms are 'My emotional state e.g. feeling down, lonely, anxious or empty'. Responses were on a similar five-point Likert scale and those who recorded 'agree' and 'strongly agree' on either item were coded as having made a psychological attribution.

Patients' worry about health was assessed using the three items from the Whiteley Index (Speckens et al. 1996a): 'Do you worry a lot about your health?', 'Do you often worry about the possibility you have a serious illness?' and 'If a disease is brought to your attention (e.g. on television, radio, newspapers, or by someone you know), do you worry about getting it yourself?'. Each item was scored as present or absent and a total score (0-3) calculated with a greater score indicating more worry.

Receipt of health-related financial benefits (incapacity benefit or disability living allowance) was recorded from patients' self-report.

At follow-up, patients were asked to complete a five-point self-rated scale of Clinical Global Improvement (CGI) which asked the patients to compare their current 'general health' with that when they first attended the neurology clinic on a five-point scale ('much worse'; 'worse'; 'not changed'; 'better'; 'much better') (Guy, 1976). They were also asked to make the same rating for improvement in their presenting symptoms (IPS).

\section{Analysis}

First we computed the mean baseline symptoms score, SF12 physical function score and total HADS score for the full sample and compared the whole baseline sample with those on whom we had follow-up data using $t$ tests and $\chi^{2}$ tests as appropriate. We then described outcome on the CGI and IPS scales. The CGI health score was used to define two groups: good outcome (CGI: 'much better' or 'somewhat better') and poor outcome (CGI: 'just the same', 'somewhat worse', 'much worse').

We determined predictors of poor outcome using logistic regression models to describe the relationship between the baseline covariates and outcome. This was done by calculating both univariate and fully adjusted multivariate odds ratios, and the corresponding $95 \%$ confidence intervals. Continuous and ordinal variables were grouped rather than making the strong assumption of linear relationships between the measure and the log odds of poor outcome. When the grouped odds ratios did clearly show a linear effect, we ran sensitivity analyses taking the corresponding variables as continuous. We quantified the proportion of the variability in outcome explained by the regression models using Nagelkerke's $R^{2}$, an analogue for logistic regression of $R^{2}$, the coefficient of determination.

\section{Ethical approval}

Ethical approval for the study was granted by a Multicentre Research Ethics Committee.

\section{Results}

\section{Recruitment and follow-up}

Recruitment is described in Fig. 1. A total of 3781 patients participated in the study representing $91 \%$ (3781 out of 4161) of those attending the designated clinics. Neurologists rated 1144 of these patients $(30 \%$ of the total) as having symptoms that were unexplained by disease [446 out of $3781(12 \%)$ were 'not at all explained' and 698 out of 3781 (18\%) were 'somewhat explained' by disease].

The 12-month outcome data were available on 716 (63\%) out of the 1144 of the recruited sample. This analysed sample was similar to the initial sample on most measured variables but had fewer males and a lower average HADS score (see Table 1). Although 


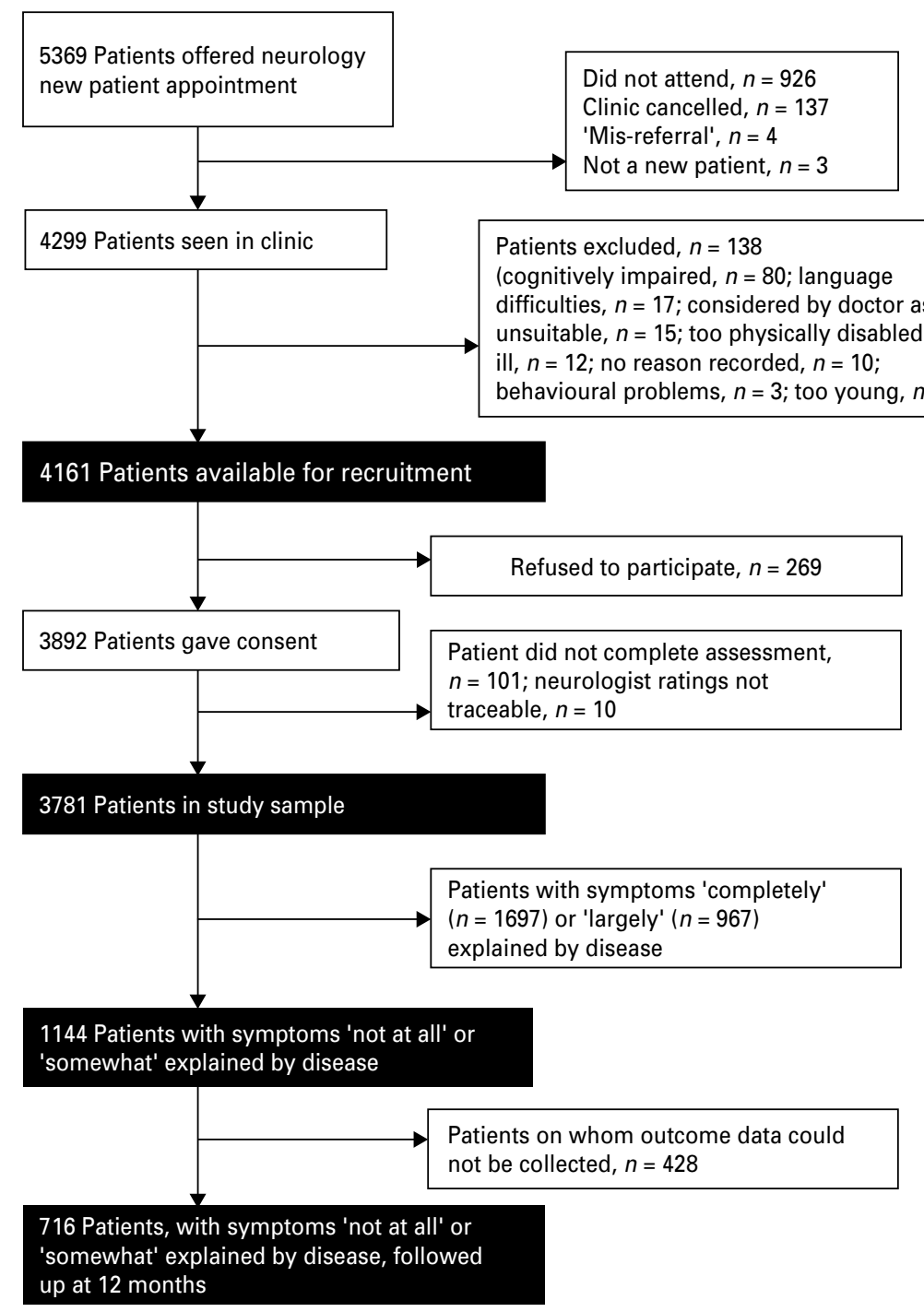

Fig. 1. Study flow chart.

statistically significant, the differences on these variables were not substantial.

\section{Outcome}

At follow-up, poor outcome ('unchanged', 'worse' or 'much worse') was reported by $482(67 \%)$ out of 716 patients on the CGI and by 422 (59\%) out of 714 patients on the IPS. All categories of outcome are shown in Table 2 and Fig. 2.

\section{Predictors of poor outcome}

In the univariate analysis (see Table 3) poor outcome, as measured by the CGI health score, was predicted by older age, poorer physical functioning, greater symptom count, greater emotional distress, an expectation of non-recovery, not attributing symptoms to psychological factors and the receipt of health-related financial benefits measured at the initial assessment. Sex and worry about health did not predict outcome. (In a sensitivity analysis treating the grouped variables as continuous the only substantive change was for symptom count, where the $p$ value decreased from 0.07 to 0.002 .)

In the multivariate analysis (see Table 3) the only strong independent predictors of a poor outcome were the patients' beliefs in expectation of non-recovery, non-attribution of symptoms to psychological factors, and the receipt of health-related financial benefits at the time of the initial consultation. Each of these three factors was associated with approximately a doubling of the odds of a poor outcome. The HADS emotional distress score was of only borderline statistical significance $(p=0.043)$ and without a clear 'dose-response' effect. When the grouped variables 
Table 1. Description of baseline variables of patients with symptoms unexplained by disease, on which 12-month data were available, compared with those patients on whom these data were missing

\begin{tabular}{|c|c|c|c|}
\hline Baseline variable & $\begin{array}{l}\text { Follow-up } \\
\text { data }\end{array}$ & $\begin{array}{l}\text { No follow-up } \\
\text { data }\end{array}$ & $p^{\mathrm{a}}$ \\
\hline Sample size, $n$ & 716 & 428 & \\
\hline Mean age, years (S.D.) & $46(14)$ & $40(14)$ & $<0.001$ \\
\hline Males, $n(\%)$ & $226(32)$ & $171(40)$ & 0.004 \\
\hline Disease 'not at all explained', $n(\%)$ & $280(39)$ & $166(39)$ & 0.91 \\
\hline Mean total symptom count, 13 items (s.D.) & $5.5(3.1)$ & $5.8(3.2)$ & 0.10 \\
\hline Mean SF12 physical function (S.D.) & $63(38)$ & $65(38)$ & 0.57 \\
\hline Mean total HADS distress score ${ }^{\mathrm{b}}$ (s.D.) & $13.3(8.7)$ & $14.8(9.2)$ & 0.006 \\
\hline Negative expectation of recovery ${ }^{c}, n(\%)$ & $276(39)$ & $158(37)$ & 0.65 \\
\hline Psychological attribution ${ }^{\mathrm{d}}, n(\%)$ & $353(49)$ & $203(48)$ & 0.62 \\
\hline Mean illness worry score ${ }^{\mathrm{e}}$ (S.D.) & $0.84(1.01)$ & $0.93(0.99)$ & 0.13 \\
\hline In receipt of financial benefits, $n(\%)$ & $197(28)$ & $110(26)$ & 0.54 \\
\hline Neurological diagnosis, $n(\%)$ & & & 0.22 \\
\hline Disease with unexplained symptoms & $182(25)$ & $111(26)$ & \\
\hline Headache diagnosis & $176(25)$ & $116(27)$ & \\
\hline Conversion symptoms ${ }^{\mathrm{f}}$ & $124(17)$ & $85(20)$ & \\
\hline Other, e.g. pain, fatigue & $234(33)$ & $116(27)$ & \\
\hline \multicolumn{4}{|c|}{ S.D., Standard deviation; HADS, Hospital Anxiety and Depression Scale; SF12, } \\
\hline \multicolumn{4}{|c|}{${ }^{a}$ Means were compared using $t$ tests and the other variables were compared } \\
\hline \multicolumn{4}{|l|}{ using $\chi^{2}$ tests. } \\
\hline \multicolumn{4}{|c|}{${ }^{\mathrm{b}}$ Total HADS is the sum of the depression and anxiety scales. } \\
\hline \multicolumn{4}{|c|}{${ }^{c}$ Negative expectation of recovery was defined as 'agree' and 'strongly agree' } \\
\hline \multicolumn{4}{|c|}{$\begin{array}{l}\text { with the statement 'My symptoms are likely to be permanent rather than temporary'. } \\
\text { d Psychological attribution was defined as 'agree' and 'strongly agree' to at least }\end{array}$} \\
\hline \multicolumn{4}{|c|}{ one of the following statements: 'Possible causes of my symptoms are stress } \\
\hline \multicolumn{4}{|c|}{ or worry' or 'My emotional state e.g. feeling down, lonely, anxious or empty'. } \\
\hline \multicolumn{4}{|c|}{${ }^{\mathrm{e}}$ On scale of 0 to 3 , with a greater score indicating more worry. } \\
\hline \multicolumn{4}{|c|}{${ }^{\mathrm{f}}$ Weakness, sensory symptoms, attacks resembling epilepsy or movement } \\
\hline
\end{tabular}

Table 2. Outcome at 12 months on Clinical Global Improvement scale $(n=716)$ and on Improvement in Presenting Symptom scale $(n=714)$

\begin{tabular}{lllllr}
\hline Outcome variable & Much worse & Worse & No change & Better & Much better \\
\hline Clinical Global Improvement, $n(\%)$ & $20(3)$ & $116(16)$ & $346(48)$ & $161(22)$ & $73(10)$ \\
Improvement in Presenting Symptom scale, $n(\%)$ & $20(3)$ & $104(15)$ & $288(41)$ & $179(25)$ & $113(16)$ \\
\hline
\end{tabular}

were included in the model as being continuous, the $p$ value for the HADS distress score changed to 0.14 , and the $p$ value for age to 0.045 . Substituting the 22-item symptom score (with additional neurological symptoms) for the 13-item score made no substantial difference to the model, indicating that adding common neurological symptoms to the score made no difference.
Nagelkerke's $R^{2}$ was $13 \%$ for the model including only the three strong independent predictors and was $16 \%$ for the full multivariate model including all of the 10 variables listed in Table 3. Thus, although each of the three highlighted variables were independently associated with approximately a doubling of the odds of a poor outcome, they collectively accounted for only a small proportion of the variability in outcome. The 


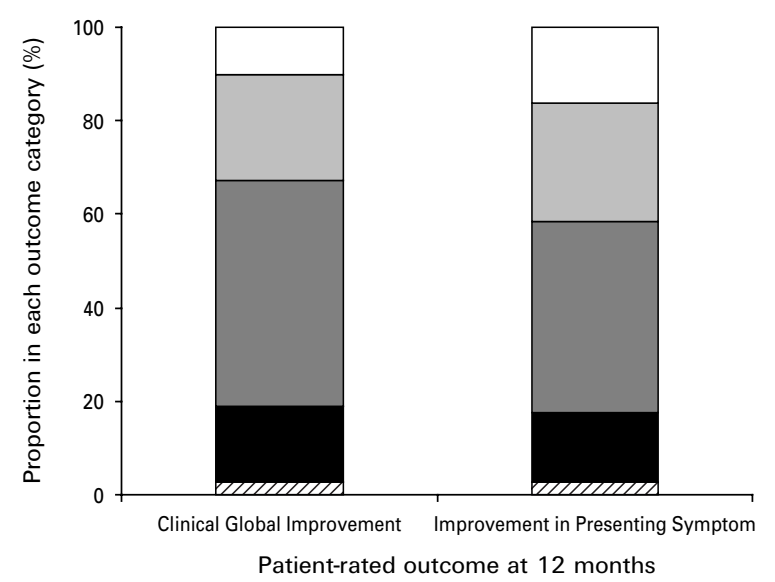

Fig. 2. Patient-rated outcome ( $\square$, much better; $\square$, better; $\square$, no change; $\mathbf{\square}$, worse; $\varangle$, much worse) at 12 months on 'Clinical Global Improvement' and 'Improvement in Presenting Symptom' Likert scales.

remaining seven variables added very little predictive power. This also demonstrates that the lack of statistical significance of the additional variables in the multivariate model was not due to correlated covariates masking the effects of each other.

\section{Discussion}

This is, to our knowledge, the first large prospective multi-centre study of predictors of outcome for neurology out-patients with symptoms rated as unexplained by disease. We found that the outcome for these patients was surprisingly poor; only a third rated themselves as improved in health 1 year after the initial neurology consultation. Poor outcome was best predicted by the patients' own beliefs (about the likely outcome of their symptoms, and the role of psychological factors in causing them), and by the reported receipt of health-related financial benefits. Contrary to our initial hypotheses, outcome was not independently predicted by the baseline number of physical symptoms that patients reported, the reported severity of their disability, the degree of emotional distress or by their reported general worry about health. Nor was it explained by the degree to which the neurologist regarded the symptoms to be unexplained by disease.

The main strength of this study is that it included a large representative sample of new neurology outpatients. All four Scottish neurology centres (serving a population of five million people), almost every Scottish neurologist and most $(91 \%)$ of the eligible patients participated. The initial sample can therefore be regarded as representative of out-patient general neurological practice, at least in the UK NHS.
The study also had limitations: First, we did not achieve complete follow-up; despite our best efforts we were unable to obtain outcome data from $37 \%$ of the sample. There were, however, no substantial baseline differences between those on whom we did have outcome data and those with missing data (not surprisingly those with missing data included a greater proportion of younger persons and males). Furthermore, selection bias with respect to the covariates is less of a limitation for regression modelling than it is for estimating event rates. Second, it might be argued that poor outcome may in some cases have been due to the development of disease. This was not the case, however (data reported elsewhere). Furthermore, the degree to which symptoms were explained by disease at baseline did not predict outcome. Third, we did not obtain a systematic description of treatment given by neurologists or others in the interval between baseline and follow-up. However, the study represents the naturalistic outcome for such patients in NHS practice and the evidence we do have suggests that few specific treatments were given. Fourth, although each of the three main variables in our multivariate model was associated with doubling the odds for poor outcome, together they only accounted for a modest amount of variance in outcome. This probably reflects the complexity of factors that determine outcome for patients with this diagnosis. Fifth, there are other potential predictors of outcome that we did not measure. For example, recently published studies of symptom outcome have included a wider range of patient illness beliefs (Frostholm et al. 2007; Foster et al. 2008), whereas others have highlighted the role of duration of symptoms, patient personality, or changes in personal relationships, family problems and social circumstances in predicting outcome (Craig et al. 1994; Crimlisk et al. 1998; Reuber et al. 2007b), none of which we measured. Sixth, we measured the outcome with a global self-rated measure of improvement. Whilst the patients' rating of improvement in their main symptoms was similar, it was not identical and other more specific measures such as that of other symptoms or disability may have given different results (Reuber et al. 2005). In addition, ratings by persons other than the patient, such as the physician or a family member, or more 'objective' outcomes such as return to work may also have produced different results.

Other studies have reported a poor outcome for patients who present with symptoms unexplained by disease (Speckens et al. 1996b). This has especially been the case for patients who have been referred to specialist medical services (Couprie et al. 1995; Barsky et al. 1996; Vercoulen et al. 1996; Crimlisk et al. 1998; Carson et al. 2003). However, we know little about 
Table 3. Univariate and multivariate analysis of predictors of poor outcome at 12 months

\begin{tabular}{|c|c|c|c|c|c|c|}
\hline \multirow[b]{2}{*}{ Variable } & \multirow[b]{2}{*}{ Total $n$} & \multirow[b]{2}{*}{$\begin{array}{l}\text { Poor } \\
\text { outcome, } \\
n(\%)\end{array}$} & \multicolumn{2}{|c|}{ Univariate analysis } & \multicolumn{2}{|c|}{ Multivariate analysis } \\
\hline & & & $\begin{array}{l}\text { OR for poor } \\
\text { outcome } \\
(95 \% \mathrm{CI})\end{array}$ & $p$ & $\begin{array}{l}\text { Adjusted OR for } \\
\text { poor outcome } \\
(95 \% \mathrm{CI})\end{array}$ & $\begin{array}{l}\text { Adjusted } \\
p\end{array}$ \\
\hline Age, years & 716 & 482 & & 0.003 & & 0.13 \\
\hline$\leqslant 35$ & 173 & $97(56)$ & 1.0 & & 1.0 & \\
\hline $36-45$ & 197 & $134(68)$ & $1.67(1.09-2.55)$ & & $1.51(0.95-2.38)$ & \\
\hline $46-55$ & 170 & $123(72)$ & $2.05(1.31-3.22)$ & & $1.67(1.02-2.73)$ & \\
\hline$\geqslant 56$ & 176 & $128(73)$ & $2.09(1.34-3.27)$ & & $1.61(0.98-2.65)$ & \\
\hline Sex & 716 & 482 & & 0.84 & & 0.88 \\
\hline Male & 226 & $150(66)$ & 1.0 & & 1.0 & \\
\hline Female & 490 & $332(68)$ & $1.06(0.76-1.49)$ & & $1.03(0.70-1.50)$ & \\
\hline 'Organicity' & 716 & 482 & & 0.29 & & 0.67 \\
\hline 'Not at all explained' & 280 & $182(65)$ & 1.0 & & 1.0 & \\
\hline 'Somewhat explained' & 436 & $300(69)$ & $1.19(0.86-1.63)$ & & $1.08(0.76-1.53)$ & \\
\hline Symptom count & 713 & 480 & & 0.07 & & 0.62 \\
\hline $0-2$ & 134 & $79(59)$ & 1.0 & & 1.0 & \\
\hline $3-5$ & 243 & $162(67)$ & $1.39(0.90-2.15)$ & & $1.08(0.67-1.76)$ & \\
\hline $6-8$ & 208 & $145(70)$ & $1.60(1.02-2.52)$ & & $1.24(0.73-2.12)$ & \\
\hline $9-13$ & 128 & $94(73)$ & $1.92(1.14-3.24)$ & & $0.87(0.43-1.74)$ & \\
\hline SF12 physical function & 716 & 482 & & $<0.001$ & & 0.93 \\
\hline 0 & 130 & $107(82)$ & $3.21(1.94-5.33)$ & & $1.35(0.68-2.67)$ & \\
\hline 25 & 67 & $52(78)$ & $2.40(1.29-4.45)$ & & $1.26(0.61-2.60)$ & \\
\hline 50 & 109 & $74(68)$ & $1.46(0.92-2.32)$ & & $1.14(0.67-1.94)$ & \\
\hline 75 & 109 & $71(65)$ & $1.29(0.82-2.04)$ & & $1.06(0.64-1.76)$ & \\
\hline 100 & 301 & $178(59)$ & 1.0 & & 1.0 & \\
\hline HADS distress & 714 & 480 & & 0.005 & & 0.043 \\
\hline $0-7$ & 208 & $136(65)$ & 1.0 & & 1.0 & \\
\hline $8-14$ & 226 & $134(59)$ & $0.77(0.52-1.14)$ & & $0.75(0.48-1.16)$ & \\
\hline $15-21$ & 159 & $118(74)$ & $1.52(0.97-2.40)$ & & $1.47(0.84-2.56)$ & \\
\hline$\geqslant 22$ & 121 & $92(76)$ & $1.68(1.01-2.79)$ & & $1.35(0.68-2.67)$ & \\
\hline $\begin{array}{l}\text { Negative expectation } \\
\text { of recovery }\end{array}$ & 713 & 479 & & $<0.001$ & & $<0.001$ \\
\hline No & 437 & $261(60)$ & 1.0 & & 1.0 & \\
\hline Yes & 276 & $218(79)$ & $2.53(1.79-3.59)$ & & $2.04(1.40-2.96)$ & \\
\hline $\begin{array}{l}\text { Psychological } \\
\text { attribution }\end{array}$ & 716 & 482 & & 0.002 & & $<0.001$ \\
\hline No & 363 & $265(73)$ & $1.69(1.24-2.32)$ & & $2.22(1.51-3.26)$ & \\
\hline Yes & 353 & $217(61)$ & 1.0 & & 1.0 & \\
\hline Illness worry & 712 & 480 & & 0.45 & & 0.55 \\
\hline 0 & 361 & $235(65)$ & 1.0 & & 1.0 & \\
\hline 1 & 169 & $120(71)$ & $1.31(0.88-1.95)$ & & $1.24(0.80-1.93)$ & \\
\hline 2 & 117 & $78(67)$ & $1.07(0.69-1.67)$ & & $1.06(0.63-1.77)$ & \\
\hline 3 & 65 & $47(72)$ & $1.40(0.78-2.51)$ & & $1.54(0.78-3.04)$ & \\
\hline Receipt of benefits & 713 & 479 & & $<0.001$ & & 0.002 \\
\hline No & 516 & $316(61)$ & 1.0 & & 1.0 & \\
\hline Yes & 197 & $163(83)$ & $3.03(2.01-4.57)$ & & $2.30(1.37-3.86)$ & \\
\hline
\end{tabular}

OR, Odds ratio; CI, confidence interval; SF12, Medical Outcomes Study Short-Form 12-item Scale; HADS, Hospital Anxiety and Depression Scale.

a Global Clinical Improvement rated as 'just the same', 'somewhat worse' or 'much worse'. 
what patient characteristics predict poor outcome. The finding that patients' beliefs about their symptoms were strong independent predictors of outcome, whereas variables such as number of reported symptoms and self-rated disability was not, surprised us. There is, however, evidence from studies of other conditions that patients' beliefs about their illness can predict outcome (Petrie et al. 2007). The belief that one will not recover has been found to predict poor subjective outcome for patients suffering from pain and patients who have had surgery, a myocardial infarction or a major injury (Mondloch et al. 2001; Cole et al. 2002; Holm et al. 2008). Whilst this association might simply reflect patients repeating the prognostication given to them by their doctors, this seems an unlikely explanation for symptoms unexplained by disease. These predictions are therefore likely to be the patients' own. The power of the patients' own prediction might mean that they are able to predict their outcome because of personal knowledge. It is also possible that such a belief plays a causal role in shaping outcome by acting as a self-fulfilling prophecy; that is if a person starts to think and behave as if they have a permanent illness, that is what they actually get.

The other belief that predicted outcome in our study was non-attribution of symptoms to psychological causes. This has been previously reported to predict outcome for patients with the chronic fatigue syndrome (Joyce et al. 1997) and also for patients with non-epileptic attack disorder (Ettinger et al. 1999). The failure of patients to agree with the doctor in attributing somatic symptoms to psychological causes is the essence of the idea of somatization (Lipowski, 1987). The concept is, however, now widely regarded as overly simplistic, as chronic somatic symptoms, whether associated with disease or not, are all likely to have multiple biological, psychological and social perpetuating factors (Sharpe et al. 2006). A tendency not to make a link between symptoms and stress or emotional problems could, however, contribute to a poor outcome by leading to a failure to address relevant psychological and social problems.

The finding that being in receipt of financial benefits at the time of the initial consultation also predicted poor outcome will perhaps not come as a surprise to many clinicians. The receipt of such benefits has been reported to predict a poorer outcome in patients with a wide range of conditions both unexplained and explained by disease. They include back pain associated with a herniated lumbar disc (Atlas et al. 2006), closed head injury (Binder \& Rohling, 1996) and neck pain (Landers et al. 2007). Whilst the explanation for this association remains uncertain, a causal relationship is supported by a study of whiplash injury which found that absence of compensation was associated with quicker subjective recovery (Cassidy et al. 2000), and a pilot study of psychotherapy for neurological symptoms unexplained by disease found that financial benefits predicted poorer outcome from treatment (Reuber et al. 2007a). Hence, it is possible that payment consequent on having symptoms and disability acts to perpetuate them.

We also found that some of our hypothesized predictors did not independently predict poor outcome. The number of somatic symptoms that the patient reports has been a key variable in differentiating somatoform disorders from simple symptoms problems (Mayou et al. 2005) and has previously been found to predict outcome in medical patients (Jackson \& Passamonti, 2005; Jackson et al. 2006). We found it to be a predictor of outcome but only in the univariate analysis (and if entered as a continuous variable); it dropped out of the multivariate model. Similarly, poorer physical functioning and greater emotional distress were predictors in the univariate analysis but did not contribute to the multivariate model (HADS did but only in a minor and non-linear fashion). General worry about health predicted in neither model. Hence, specific patient-reported illness beliefs and receipt of benefits proved to be better predictors of patients' outcome than these more general patient characteristics of symptoms, distress and functioning which are more commonly recorded at assessment.

The finding of an association of poor subjective outcome with specific beliefs and being in receipt of health-related financial benefits in patients with symptoms unexplained by disease has important implications. First, asking about these factors may assist the assessing clinician in predicting poor outcome 1 year later. Second, they may point the way to a greater understanding of the psychological and social mechanisms that determine poor outcome. Third, they lend support to the idea that interventions which change these variables may improve the outcome for this patient group. As well as providing theoretical underpinning for the application of cognitive behaviour therapy (Kroenke \& Swindle, 2000) they suggest that doctors should take time to discuss their patients' own beliefs about their illness. Similarly they emphasize that those policies that determine health-related financial benefits may need to be amended if we are to maximize the chance of recovery (Waddell et al. 2007).

\section{Conclusion}

A large proportion of patients assessed by a neurologist as having symptoms not at all or only somewhat explained by disease had a poor self-rated outcome a 
year after the initial specialist consultation and this was predicted by the patients' beliefs and receipt of financial benefits.

\section{Appendix}

\section{Guidance given to doctors on 'What we mean by} organic disease'

The following is meant as a guide for this study and we are aware that any divisions like this are imperfect. Many patients have a mixture of symptoms, syndromes or disease and the final coding is your decision based on these guidelines.

\section{'Not organic disease'}

For the purpose of this study this includes: tension headache; aetiologically controversial symptom 'syndromes' (e.g. fibromyalgia, irritable bowel syndrome); physiologically explained processes which are thought to be linked to emotional symptoms (e.g. hyperventilation); emotional disorders (e.g. depression, anxiety, panic disorder).

\section{'Organic disease'}

For the purpose of this study this includes: migraine; any neurological disorder with a known pathological basis; neurological disorders with defined and characteristic features but without a clear pathological basis (e.g. Gilles de la Tourette syndrome, idiopathic focal dystonia); physiological explained processes NOT linked to emotional symptoms (e.g. micturition syncope); psychotic disorder.

\section{Acknowledgements}

We thank the staff and patients of the participating clinics and all the neurologists and general practitioners who took part in this study: S. Tennant, L. Alder, J. Sim, M. Selkirk, D. McConachie - the researchers who administered the questionnaires.

\section{Declaration of Interest}

This work was supported by the Scottish Chief Scientist Office and NHS Quality Improvement Scotland (QIS). None of the authors has any relevant financial interests.

\section{References}

Atlas SJ, Chang Y, Keller RB, Singer DE, Wu YA, Deyo RA (2006). The impact of disability compensation on long-term treatment outcomes of patients with sciatica due to a lumbar disc herniation. Spine 31, 3061-3069.
Barsky AJ, Ahern DK, Bailey ED, Delamater BA (1996). Predictors of persistent palpitations and continued medical utilization. Journal of Family Practice 42, 465-472.

Binder LM, Rohling ML (1996). Money matters: a meta-analytic review of the effects of financial incentives on recovery after closed-head injury. American Journal of Psychiatry 153, 7-10.

Bombardier CH, Buchwald DS (1995). Outcome and prognosis of patients with chronic fatigue vs chronic fatigue syndrome. Archives of Internal Medicine 155, 2105-2110.

Carson AJ, Best S, Postma K, Stone J, Warlow C, Sharpe M (2003). The outcome of neurology outpatients with medically unexplained symptoms: a prospective cohort study. Journal of Neurology, Neurosurgery and Psychiatry 74, 897-900.

Carson AJ, Ringbauer B, Stone J, McKenzie L, Warlow C, Sharpe M (2000). Do medically unexplained symptoms matter? A prospective cohort study of 300 new referrals to neurology outpatient clinics. Journal of Neurology, Neurosurgery and Psychiatry 68, 207-210.

Cassidy JD, Carroll LJ, Cote P, Lemstra M, Berglund A, Nygren A (2000). Effect of eliminating compensation for pain and suffering on the outcome of insurance claims for whiplash injury. New England Journal of Medicine 342, 1179-1186.

Cole DC, Mondloch MV, Hogg-Johnson S (2002). Listening to injured workers: how recovery expectations predict outcomes - a prospective study. Canadian Medical Association Journal 166, 749-754.

Couprie W, Wijdicks EF, Rooijmans HG, van Gijn J (1995). Outcome in conversion disorder: a follow up study. Journal of Neurology, Neurosurgery and Psychiatry 58, 750-752.

Craig TK, Drake H, Mills K, Boardman AP (1994). The South London Somatisation Study. II. Influence of stressful life events, and secondary gain. British Journal of Psychiatry 165, 248-258.

Crimlisk HL, Bhatia K, Cope H, David A, Marsden CD, Ron MA (1998). Slater revisited: 6 year follow up study of patients with medically unexplained motor symptoms. British Medical Journal 316, 582-586.

Ettinger AB, Devinsky O, Weisbrot DM, Ramakrishna RK, Goyal A (1999). A comprehensive profile of clinical, psychiatric, and psychosocial characteristics of patients with psychogenic nonepileptic seizures. Epilepsia 40, 1292-1298.

Foster NE, Bishop A, Thomas E, Main C, Horne R, Weinman J, Hay E (2008). Illness perceptions of low back pain patients in primary care: what are they, do they change and are they associated with outcome? Pain 136, 177-187.

Frostholm L, Oernboel E, Christensen KS, Toft T, Olesen F, Weinman J, Fink P (2007). Do illness perceptions predict health outcomes in primary care patients? A 2-year follow-up study. Journal of Psychosomatic Research 62, 129-138.

Gureje O, Simon GE, Ustun TB, Goldberg DP (1997). Somatization in cross-cultural perspective: a World Health Organization study in primary care. American Journal of Psychiatry 154, 989-995. 
Guy W (1976). Clinical Drug Evaluation (ECDEU) Assessment Manual. National Institute of Mental Health: Rockville, MD.

Holm LW, Carroll LJ, Cassidy JD, Skillgate E, Ahlbom A (2008). Expectations for recovery important in the prognosis of whiplash injuries. PLoS Medicine 5, e105.

Jackson J, Fiddler M, Kapur N, Wells A, Tomenson B, Creed F (2006). Number of bodily symptoms predicts outcome more accurately than health anxiety in patients attending neurology, cardiology, and gastroenterology clinics. Journal of Psychosomatic Research 60, 357-363.

Jackson JL, Passamonti M (2005). The outcomes among patients presenting in primary care with a physical symptom at 5 years. Journal of General Internal Medicine 20, 1032-1037.

Joyce J, Hotopf M, Wessely S (1997). The prognosis of chronic fatigue and chronic fatigue syndrome: a systematic review. Quarterly Journal of Medicine 90, 223-233.

Kroenke K (2003). Patients presenting with somatic complaints: epidemiology, psychiatric co-morbidity and management. International Journal of Methods in Psychiatric Research 12, 34-43.

Kroenke K, Jackson JL (1998). Outcome in general medical patients presenting with common symptoms: a prospective study with a 2-week and a 3-month follow-up. Family Practice 15, 398-403.

Kroenke K, Spitzer RL, Williams JB (2002). The PHQ-15: validity of a new measure for evaluating the severity of somatic symptoms. Psychosomatic Medicine 64, 258-266.

Kroenke K, Swindle R (2000). Cognitive-behavioral therapy for somatization and symptom syndromes: a critical review of controlled clinical trials. Psychotherapy and Psychosomatics 69, 205-215.

Landers MR, Cheung W, Miller D, Summons T, Wallmann HW, McWhorter JW, Druse T (2007). Workers' compensation and litigation status influence the functional outcome of patients with neck pain. Clinical Journal of Pain 23, 676-682.

Lempert T, Dieterich M, Huppert D, Brandt T (1990). Psychogenic disorders in neurology: frequency and clinical spectrum. Acta Neurologica Scandinavica 82, 335-340.

Lipowski ZJ (1987). Somatization: the experience and communication of psychological distress as somatic symptoms. Psychotherapy and Psychosomatics 47, 160-167.

Mayou R, Kirmayer LJ, Simon G, Kroenke K, Sharpe M (2005). Somatoform disorders: time for a new approach in DSM-V. American Journal of Psychiatry 162, 847-855.

Mondloch MV, Cole DC, Frank JW (2001). Does how you do depend on how you think you'll do? A systematic review of the evidence for a relation between patients' recovery expectations and health outcomes. Canadian Medical Association Journal 165, 174-179.

Petrie KJ, Jago LA, Devcich DA (2007). The role of illness perceptions in patients with medical conditions. Current Opinion in Psychiatry 20, 163-167.

Reuber M, Burness C, Howlett S, Brazier J, Grünewald R $(2007 a)$. Tailored psychotherapy for patients with functional neurological symptoms: results of a pilot study. Journal of Psychosomatic Research 63, 625-632.

Reuber M, Howlett S, Khan A, Grünewald R (2007b). Non-epileptic seizures and other functional neurological symptoms: predisposing, precipitating and perpetuating factors. Psychosomatics 48, 230-238.

Reuber M, Mitchell AJ, Howlett S, Elger CE (2005). Measuring outcome in psychogenic nonepileptic seizures: how relevant is seizure remission? Epilepsia 46, 1788-1795.

Sharpe M (2002). Medically unexplained symptoms and syndromes. Clinical Medicine 2, 501-504.

Sharpe M, Mayou R, Walker J (2006). Bodily symptoms: new approaches to classification. Journal of Psychosomatic Research 60, 353-356.

Speckens AE, Spinhoven P, Sloekers PP, Bolk JH, Van Hemert AM (1996a). A validation study of the Whitely Index, the Illness Attitude Scales, and the Somatosensory Amplification Scale in general medical and general practice patients. Journal of Psychosomatic Research 40, 95-104.

Speckens AE, Van Hemert AM, Bolk JH, Rooijmans HG, Hengeveld MW (1996b). Unexplained physical symptoms: outcome, utilization of medical care and associated factors. Psychological Medicine 26, 745-752.

Vercoulen JH, Swanink CM, Fennis JF, Galama JM, Van der Meer JW, Bleijenberg G (1996). Prognosis in chronic fatigue syndrome (CFS) : a prospective study on the natural course. Journal of Neurology, Neurosurgery and Psychiatry 60, 489-494.

Waddell G, Burton K, Aylward M (2007). Work and common health problems. Journal of Insurance Medicine 39, 109-120.

Ware Jr. J, Kosinski M, Keller SD (1996). A 12-Item Short-Form Health Survey: construction of scales and preliminary tests of reliability and validity. Medical Care 34, 220-233.

Weinman J, Petrie KJ, Moss-Morris R, Horne R (1996). The illness perception questionnaire: a new method for assessing the cognitive representation of illness. Psychology and Health 11, 431-445.

Zigmond AS, Snaith RP (1983). The Hospital Anxiety and Depression Scale. Acta Psychiatrica Scandinavica 67, 361-370. 